\title{
Sirolimus is an Usual Drug for Drug-eluting Stents but a New Drug for Drug-eluting Balloons
}

\author{
Kaori Nakagawa' ${ }^{1}$ Fumiaki Ikeno ${ }^{2}$
}

T he drug-eluting balloon is a promising device to address the unmet needs of the current treatment of cardiovascular disease through catheters. In Europe, drug-eluting balloons from several manufacturers have been approved for use in clinical practice, and abundant evidence on the treatment of both peripheral vascular disease and coronary artery disease has been published. ${ }^{1,2}$

\section{See page 133}

There are three important components in drugeluting balloon technology. One is the drug, the other is the balloon catheter, and the last is the excipient that binds the drug to the balloon catheter surface and releases it to the vessel wall. It is a surprising fact that all drug-eluting balloons currently approved in Europe use the same drug (paclitaxel), unlike the situation with drug-eluting stents, as most stents use drugs from the 'limus family'. Paclitaxel is an antiproliferative and lipophilic drug, and it is believed that these features allow for rapid infiltration and cell proliferation suppression. ${ }^{3}$ Considering that sirolimus in drug-eluting stents has a more potent antiproliferative effect than paclitaxel, ${ }^{4}$ sirolimus may be beneficially used for local release of the drug in association with the balloon catheter. Both drugs are hydrophobic, and it is natural to expect them to have similar release patterns. Furthermore, it is expected that the excipient will be further improved. This component, perhaps, is the key component of drug-eluting balloons, as the other two components are the same in all balloons, and it may differentiate them regarding their efficiency.

In the study published by Takimura et al. ${ }^{5}$ in this issue of Revista Brasileira de Cardiologia Invasiva, the authors tested a new drug-eluting balloon using sirolimus instead of paclitaxel in a preclinical study. Although several groups are currently testing drugs from the 'limus family' in drugeluting balloons in preclinical studies, ${ }^{6,7}$ no balloon that uses sirolimus has been approved for use in daily practice. As their clinical efficacy is yet to be clearly established, the industry cannot take the risk of making large expenditures on research and development with a well-known drug in drug-eluting stents; thus, the companies tend to select a 'me-too' drug", such as paclitaxel.

In the study by Takimura et al., ${ }^{5}$ a single excipient is used to release sirolimus. This device uses synthetic nanoparticles and consists of a double phospholipid membrane that contains sirolimus. In previously published data, in vitro tests showed both stable adhesion of the balloon coating and a smooth, uniform and regular surface, without folds or fractures. ${ }^{8,9}$ Furthermore, in sirolimus-coated balloons, after brief exposure to the arterial wall of 60 seconds, these nanoparticles were initially found on the endothelial surface, followed by the middle layer and, finally, deeper layers, such as the adventitia. ${ }^{10}$ The method of drug delivery by nanoparticles is relatively new, but several groups have tested nanoparticles in drug-eluting devices used in cardiovascular interventionist treatment. ${ }^{11,12}$ To test the clinical relevance of this new technology in drug-eluting balloons after bench testing, the next step will be to study their efficacy in preclinical trials.

Takimura et al. ${ }^{5}$ successfully demonstrated the efficacy of this new drug-eluting balloon using sirolimus and nanoparticles in different excipient:drug formulations through optical coherence tomography and histopathology in a healthy porcine model. Dose dependence was observed regarding the effectiveness of neointimal proliferation inhibition, with little inflammation or damage as the excipient concentration increased. ${ }^{5}$

\footnotetext{
* Pharmacology - A popular term for a generic drug with an identical formulation and stated indications as a previously FDA-approved agent; MTDs are usually approved 'automatically' based on their virtual identity with other formulations.
}

1 PhD; Research Fellow of the Division of Cardiovascular Medicine of the School of Medicine of Stanford University, Stanford, USA

$2 \mathrm{PhD}$; Associate Researcher of the Division of Cardiovascular Medicine of the School of Medicine of Stanford University, Stanford, USA
Correspondence to: Fumiaki Ikeno. 300 Pasteur Drive, Falk Cardiovascular Research Center Stanford, CA, USA - 94305-5406

E-mail: fikeno@stanford.edu

Received on: 06/17/2012 • Accepted on: 06/18/2012 
This is one of the promising findings regarding this new device. However, to reach the clinical trial step, the device must be more thoroughly tested in the preclinical phase. Before the test phase is initiated, clinical data are required for long-term safety, evaluation of distal embolisation, pharmacokinetics and casing inflation to verify toxicity. After the test phase of this new drug-eluting balloon is finished, including clinical trials, a drug known to drug-eluting stents, sirolimus, may become a new option for drug-eluting balloons, and this new coating technology with nanoparticles may become an advancement regarding drug-eluting methods in cardiovascular intervention.

\section{CONFLICTS OF INTEREST}

Dr. Fumiaki Ikeno is a consultant for CV Ingenuity, Inc. (Fremont, USA). Kaori Nakagawa declares no conflicts of interest.

\section{REFERENCES}

1. Scheller B, Clever YP, Kelsch B, Hehrlein C, Bocksch W, Rutsch W, et al. Long-term follow-up after treatment of coronary in-stent restenosis with a paclitaxel-coated balloon catheter. JACC Cardiovasc Interv. 2012;5(3):323-30.

2. Micari A, Cioppa A, Vadala G, Castriota F, Liso A, Marchese A, et al. Clinical evaluation of a paclitaxel-eluting balloon for treatment of femoropopliteal arterial disease: 12-month results from a multicenter italian registry. JACC Cardiovasc Interv. 2012;5(3):331-8.

3. Scheller B, Speck U, Schmitt A, Bohm M, Nickenig G. Addition of paclitaxel to contrast media prevents restenosis after coronary stent implantation. J Am Coll Cardiol. 2003;42: 1415-20.

4. Birkmeier KA, Kastrati A, Byrne RA, Holle H, Schulz S, Tiroch K, et al. Five-year clinical outcomes of sirolimus-eluting versus paclitaxel-eluting stents in high-risk patients. Catheter Cardiovasc Interv. 2011;77:494-501.
5. Takimura CK, Galon MZ, Sojitra P, Doshi M, Aiello V, Gutierrez PS, et al. Estudo da dose excipiente:fármaco com avaliação da hiperplasia neointimal por tomografia de coerência óptica e histopatologia em artérias coronárias porcinas após o emprego do balão eluidor de sirolimus. Rev Bras Cardiol Invasiva. 2012;20(2):133-9.

6. Granada JF, Milewski K, Zhao H, Stankus J, Tellez A, Aboodi MS, et al. Vascular response to zotarolimus-coated balloons in injured superficial femoral arteries of the familial hypercholesterolemic swine. Circ Cardiovasc Interv. 2011;4(5):447-55.

7. Cremers B, Toner JL, Schwartz LB, von Oepen R, Speck U, Kaufels $\mathrm{N}$, et al. Inhibition of neointimal hyperplasia with a novel zotarolimus coated balloon catheter. Clin Res Cardiol. 2012;101(6):469-76.

8. Doshi M, Sherdiwala D, Sojitra P, Vyas A, Gandhi $P$ Zagabathuni M. Reestablishment of blood flow in blocked human arteries by transferring nano-encapsulated drug through medical devices, designed for the same and releasing the nano- encapsulated drug in human arteries. US 20110264188 A1, Oct 27, 2011.

9. Doshi M, Sherdiwala D, Sojitra P, Vyas A, Gandhi P. Rejuvenating coronary artery by improving blood flow with the help of insertion of nano-balls (Encapsulated nanoparticles) containing therapeutic agents by non-implantable medical device for tissues and thereby providing in-tissue release to address the required cell cycle. US 20120065584 A1, Mar 15, 2012.

10. Yasdani SNM, Sherdiwala DP, Prakash S, Kolodgie FD, Virmani R A temporal assessment of drug distribution following local balloon delivery of nanoparticle sirolimus. J Am Coll Cardiol. 2011;58 Suppl:B6.

11. Luderer F, Lobler M, Rohm HW, Gocke C, Kunna K, Kock K, et al. Biodegradable sirolimus-loaded poly(lactide) nanoparticles as drug delivery system for the prevention of in-stent restenosis in coronary stent application. J Biomater Appl. 2011;25(8):851-75.

12. Zago AC, Raudales JC, Attizzani G, Matte BS, Yamamoto Gl, Balvedi JA, et al. Local delivery of sirolimus nanoparticles for the treatment of in-stent restenosis. Catheter Cardiovasc Interv. 2012 May 4. [Epub ahead of print] 